\title{
Access Impediments to Health Care and Social Services Between Anglophone and Francophone African Immigrants Living in Philadelphia with Respect to HIV/AIDS
}

\author{
Kenneth Omollo A. Simbiri · Alice Hausman • \\ Rose O. Wadenya $\cdot$ Jeffrey Lidicker
}

Published online: 8 February 2009

(c) The Author(s) 2009. This article is published with open access at Springerlink.com

\begin{abstract}
Objectives To describe the social and cultural differences between Anglophone and Francophone African immigrants which define the impediments that Francophone African immigrants face trying to access health and human services in Philadelphia, Pennsylvania. Methods Surveys and personal interviews were administered to participants in social events, community meetings, and health centers. A Chi-squared analysis was used to contrast the communities. Results Francophone Africans demonstrated less acculturation, education, English fluency, and more legal documentation problems, and thus face greater challenges accessing health care. Anglophone Africans had a higher level of acculturation, fewer language problems, and perceived fewer barriers in accessing health care than
\end{abstract}

K. O. A. Simbiri · A. Hausman

Department of Public Health, Temple University School of Medicine, 1900 North 12th Street, Philadelphia, PA 19122, USA

K. O. A. Simbiri $(\bowtie)$

Department of Neuroscience, Center for Neurovirology, Temple University School of Medicine, 1900 North 12th Street,

Philadelphia, PA 19122, USA

e-mail: simbiri@mail.med.upenn.edu

K. O. A. Simbiri

Center for Substance Abuse Research, Temple University School of Medicine, 1900 North 12th Street, Philadelphia, PA 19122, USA

R. O. Wadenya

Department of Preventive and Restorative Sciences, University of Pennsylvania School of Dental Medicine, 1900 North

12th Street, Philadelphia, PA 19122, USA

J. Lidicker

Center for Statistical and Information Science, Temple

University School of Medicine, 1900 North 12th Street,

Philadelphia, PA 19122, USA
Francophone Africans. Conclusions Educating new immigrants, through a more culturally sensitive infectious disease treatment and prevention program, is integral to achieving a higher access and utilization rates of available services; especially in recent Francophone immigrants. A larger study is needed to extend the findings to other cities where immigrants with similar backgrounds or acculturation issues reside.

Keywords Access · HIV/AIDS - Immigrant health

\section{Background}

There are currently large African immigrant populations living in Philadelphia and other United States cities [1, 2]. Some of these new immigrants arrive HIV-infected and co-infected with TB and other parasitic diseases such as malaria, filariasis and other helminthes [3, 4]. Accordingly, the prevalence of HIV in this population is presumed to be high, though exact numbers are not available. Due to the relative rarity of parasitic co-infections in the US population, health care professionals are less familiar with the symptoms and the appropriate screening tests available to diagnose these ailments [3]. As a result, new immigrants who are already infected, remain infected and accordingly experience higher co-morbidities.

To effectively address these diseases within the African immigrant community, a host of factors must be considered, including but not limited to: the influence of poverty, education, nutrition, gender inequality, marginalization, stigmatization, language barriers, and access to health and social services [5-8].

The targeted West African immigrant population of Philadelphia, Pennsylvania that this study is focused on, is 
composed of Francophone (FP) immigrants from Senegal, the Ivory Coast, and Togo; and Anglophone (AP) immigrants from Nigeria, Liberia, and Ghana. These two populations are culturally distinct and are composed of Africans from many different countries and tribes. African immigrants from English-speaking countries formed an earlier pool of West African immigrants to the United States, while the most recent West African immigrants are mainly from French-speaking countries with minimal formal education or any of the other supports which typically aid transition to a new culture.

Because FP groups are less able to communicate in English, their opportunities for obtaining adequate health insurance are limited. Similar with other non Englishspeaking immigrant communities, the FP population is underemployed and chronically stressed [5, 8-11]. A large number of FP immigrants are refugees from their countries of origin who were forced to flee torture, detention, or death due to war [12-14]. Some arrive as from refugee camps in different countries and are prescreened for different diseases before coming to the US. Others arrive on temporary visas and overstay their visa status, while a minority entered illegally. Additionally, the majority of FP Africans are Muslim, thus they do not have access to the religious support structures that are readily available from the numerous churches that Christian AP Africans take advantage of. Because FPs came from these highly stressful situations, or situations which would engender distrust in the authorities, most tend not to seek medical or social services aid.

These differences in background make access to health care and social services more difficult for these new immigrants in comparison with other immigrants because their integration and roles within American culture is hampered by these linguistic, social and cultural conditions which affect their education and employment- two crucial factors in facilitating access to health care. Some of the literature suggests that these immigrants underutilize the health care system; the direct result being that many conditions that can be easily treated on an outpatient basis, become conditions which require emergency room visits $[15,16]$.

With the influx of Africans from FP countries to the Philadelphia area, new African immigrants face unknown internal obstacles to health and social services in comparison to earlier immigrants from AP countries. Both of the $\mathrm{AP}$ and the FP immigrant groups, but especially the FP groups in Philadelphia have remained relatively invisible and understudied in terms of obstacles to accessing health and social services. Studies and surveys in Philadelphia and other cities tend to lump Africans and African-Americans together, yet these immigrant groups are distinct and with differing health and social needs. This current study was initiated out of the observation of these differences, and that these special needs require different methods to improve access to available services.

\section{Methods}

This descriptive study is comprised of two components: a structured survey and an ethnographic site visit component composed of interviews and observations. Study participants included immigrants from AP and FP countries. Phase 1 consisted of pilot-testing on 9 AP and 9 FP members and leaders of the community, followed by Phase 2; administering a 90-item questionnaire to 239 participants (125 AP and $114 \mathrm{FP}$ ), and Phase 3; site visit observations of 15 participant's (10AP and 5FP) interactions with providers during their visits to health centers.

In Phase 1, the questionnaires were pilot-tested for clarity with 9 APs in English (3 each from Nigeria, Ghana, and Liberia) and 9 from FPs in French (3 each from Togo, Ivory Coast, and Senegal). They were asked to address the clarity, length, and sensitivity of the questions. They were asked to indicate if community issues were adequately addressed by the questions. To establish face validity, professionals familiar with the immigrant populations and with HIV/AIDS infection in West Africa reviewed the instruments. The questionnaires were reviewed and approved by Temple University and Philadelphia Department of Public Health Institutional Review Boards.

In Phase 2, self-administered questionnaires were given to participants. The target sample group was composed of 239 adult West African immigrants (125 APs and 114 FPs) residing in Philadelphia. Given the migratory nature of the target population, a convenience sample of 239 participants was selected [17]. Thirty-five to forty-two participants from each of the three FP countries with the highest immigrant populations and 37-50 participants from each of the three AP countries participated in the study. Participants were recruited during health fairs, in churches, mosques, and car washes. They decided to participate after explanation that the study was on access to health care and social services and having read the consent form in English or French as necessary. There was no monetary compensation. The interviewers were given the option of reading the questionnaire to those who consented but could not read, however all those who consented in the study were able to read English or French. In meetings, the questionnaires were administered before other agenda items for that day by the investigator and/or a trained administrator. More specifically, before giving out the survey, the administrator read aloud the consent form to the participants in either English or French, depending on the group; and explained to them that participation was voluntary and that they could 
withdraw at any point. No names were used on the surveys, and responses were kept anonymous and under lock and key, accessible only to the investigator. There were no right or wrong answers, and they were told to answer the questions as honestly and as thoroughly as possible in approximately 30-45 min. The survey administrator was available to answer questions that participants had while filling the questionnaire.

The target population was unique and a literature search revealed that no similar studies had been conducted with similar groups. The investigator designed a culturally sensitive survey instrument that addressed the most pertinent issues faced by the communities. The questions constructed in English were translated into French by four FPs who were fluent in both English and French. The translations were then given to three other FPs to translate back to English. If the translations remained the same no changes were made, but those that differed were corrected with the intended meaning made clear.

The 90 self-administered questionnaire items were broken down into the following areas: general health and social services, knowledge, attitude and belief (GKAB), knowledge, attitude, and belief regarding HIV/AIDS (SKAB). The items about general health and social services knowledge featured diseases such as TB, diabetes, heart disease, and cancer. Specific HIV/AIDS knowledge, attitude, and beliefs were addressed by specific questionnaire items such as beliefs about circumcision, wife inheritance, sex with young girls, and the spread of HIV. Social services featured their access and use of legal help, housing, and employment information. The instrument also addressed issues of social support. The social support variable, important in normal settlement and adjustment in a new community had two components (1) instrumental and emotional support (social support-1) composed of items-having someone to tell most secret worries and fears, having someone to help resolve problems, and (2) a more tangible and informational based social support (social support-2) composed of items-befriend individuals from own ethnicity, befriend Americans, spend most free time with own ethnic group members, and spend most free time with Americans. Social network, the web of relationships important in knowing one's community in terms of, for example; finding jobs, schools, and services was composed of items-visited home of a friend of a different race, visited home of a friend of a different religion, and attended religious services. Discrimination and stigma, implicated by most members of the community for the disparity in health and social services delivery, was composed of questionnaire items-denied or lost a job due to ethnicity, poor treatment at health center due to ethnicity, and mistreatment of children at school due to ethnicity. Acculturation was considered to be a major factor in successful settlement of the new immigrants in Philadelphia. The items also measured the length of stay in the US and Philadelphia, the languages used regularly, the music listened to, and the people with whom they spent their free time.

The instrument's face validity and content validity was evaluated by key members of the community and professionals in the field of HIV/AIDS familiar with African AIDS epidemic (by specifically looking at the instrument's readability, comprehension, clarity and precision of content).

In Phase 3, the site visit component of the study involved a brief demographic survey of the participants during visits to service delivery centers. Health Centers serving the communities where participants resided were identified, and three of the service centers (SCs) were chosen for the study (SC1, SC2, and SC3). Service center 1 (SC1) and SC2 were part of Philadelphia Department of Health and the third one was a private Hospital. Interpreters accompanied the FP participants who could not speak English. For the interview of the participants during the observation, the investigator used a guide encompassing access, HIV infection, HIV stigma, social support, employment, and significance of English language proficiency. The notes were transcribed at the end of the day, capturing the key themes of the interview with each participant.

\section{Statistical Analyses}

The Chi-squared statistic was used to analyze the structured survey to identify significant factors contributing to differences between APs and FPs in access to health services. All statistics were performed using SPSS version 14 (Chicago, IL).

\section{Results}

Of the total 239 participants, 125 were from AP countries, $50(20.9 \%)$ were from Nigeria, 37 (15.5\%) from Liberia, and $38(15.9 \%)$ from Ghana. One hundred and fourteen participants were from FP countries, 42 (17.6\%) were from Togo, 35 (14.6\%) from Ivory Coast, and 37 (15.5\%) from Senegal. There were more males in both groups, but significantly more females among the AP than FP. Most participants were between 31 and 50 years for both groups. APs achieved more education than FPs $(P=0.0001)$. APs had lived in the US longer than FPs $(P=0.015)$, but had lived in Philadelphia about the same length of time as FPs $(P=0.15)$. More FPs reported higher SES $(P=0.002)$ in Philadelphia than in their home countries compared to APs. There were more employed APs $(P=0.008)$, more APs 
indicating that they were professionals $(P=0.03)$, were Christian $(P<0.0001)$, and fluent in English $(P<0.0001)$ than FPs. More FPs $(P<0.0001)$ reported fluency in French and being Muslim $(P<0.0001)$. Most APs $(P<0.0001)$ health care needs were met by their primary care physicians while FPs used traditional care and ordered medicines from their native countries (Table 1).

Participant perception of the greatest barriers to access is shown in Fig. 1. It is noted that besides the language barrier, FP immigrants reported immigrant cultural insensitivity to host culture and lack of documents as major barriers to access; while APs cited host cultural insensitivity to immigrant culture, transportation, and other factors such as a lack of awareness of how the US health care system works, as barriers. During site visit interviews, FPs reported that immigrants were reluctant to adopt the American culture and were attempting to practice their cultures in their host country. APs felt that in their interactions with mainstream culture, their culture was often ignored and marginalized. Discrimination and stigma were mentioned by FPs and APs as a factor that increased the impediment to access. The analysis of specific items composing the discrimination and stigma set of questions, it was observed that when participants were asked "Have you ever been denied a job or lost a job because of your ethnic background?" of 63 respondents who stated that they had experienced discrimination, $57 \%$ were FPs and $43 \%$ were APs. From a total of 15 who reported never applying for a job, but perceiving discrimination, $31 \%$ were APs and 69\% FPs (Fig. 2).

The stigma of HIV was perceived to be a major contributing factor to the reluctance towards using the health care system by those sick with HIV or contemplating HIV testing. When asked "If a member of your family became ill with HIV, would you want it to remain a secret", APs (60\%) and FPs (40\%) reported they would not; while among those responding affirmatively, $48 \%$ were APs and $52 \%$ were FPs (Fig. 3). HIV stigma was an issue that both groups complained about in the community, so it was not surprising to find no significant difference between APs and FPs.

Significant differences were observed in the languages used. When asked "what language do you use at home?" among a total of 58 who responded to using English alone, $85 \%$ were APs, and $15 \%$ FPs; out of a total of 48 who reported using English/Ethnic, 94\% were APs and 6\% FPs, while out of a total of 21 participants reporting usage of French, 100\% were FPs, and from 12 participants reporting the use of English/French, 75\% were FPs and 25\% were APs (Table 1). More APs received their first health care at the emergency room compared to FPs. From the pilot and the in-site conversation phases of the study, we observed that because of their lack of documents, most FPs avoided health care centers including emergency room, unless they desperately had to make the visit. There were more APs going to their primary health care physicians first compared to FPs, hence the significance of transportation for APs (Table 1). APs had greater social support and network than FPs through their established churches and other group organizations (Table 2). FPs who were mainly Moslem had less social support and a smaller network-there was only one French-speaking church in the city compared to over 10 different English-speaking churches. There were five mosques in which services were conducted separately for men, women, and children.

Sources of information were also a barrier encountered by both APs and FPs. The information source that FPs used to find out about HIV was mainly the radio and newspapers. APs obtained their HIV information through the Internet, word of mouth, church sponsored health fairs, and professional journals (Table 1). However, most APs and FPs lamented that there was less information on HIV in the US, which led to their perception of low HIV prevalence. According to two participants-a former nurse from an AP region and an engineer from FP region-they had more HIV information in their countries on bill boards, buses, trains, schools, the daily papers, radio, on the TV everyday; than they were witnessing in the US.

\section{Site Visit}

The site visit study questionnaire and interviews revealed more information about barriers to access (Table 2). Site visit information from the small sample of APs and FPs indicated that language, proximity to health centers, HIV stigma, discrimination and denial, and power balance between men and women were major barriers to the access and utilization of services. The women expressed a lack of input into major decisions made in their homes. The men made all the decisions including whether to go to health centers when there was sickness in the family. This resulted with mostly negative results since men tended to avoid the health centers. The interviews also revealed that some people, especially FP men, persistently maintained risky sexual behaviors despite demonstrating high knowledge concerning HIV/AIDS.

\section{Discussion}

This formative study highlights the major barrier to access faced by AP and FP Africans in Philadelphia without disparaging the needs and more work required on the AfricanAmerican community that they are often grouped under. The main reported barriers were language, documentation, and cultural insensitivity. Harawa et al. [9] reported that immigrants living in urban areas encounter more barriers in 
Table 1 Demographic characteristics of Anglophone and Francophone West Africans in Philadelphia

\begin{tabular}{|c|c|c|c|c|c|c|c|c|}
\hline \multirow[t]{2}{*}{ Variable } & \multicolumn{2}{|c|}{ Anglophone } & \multicolumn{2}{|c|}{ Francophone } & \multicolumn{2}{|c|}{ Total } & \multirow[t]{2}{*}{$\chi^{2}$} & \multirow[t]{2}{*}{$P$ value } \\
\hline & $\#$ & $\%$ row $(\% \mathrm{col})$ & $\#$ & \%row $(\% \mathrm{col})$ & \# & $\%$ row $(\% \mathrm{col})$ & & \\
\hline Region & 125 & 53 & 114 & 47 & 239 & 100 & & \\
\hline Sex & & & & & & & 4.7 & $0.03 *$ \\
\hline Male & 78 & $48(62.4)$ & 86 & $52(75.4)$ & 164 & $100(68.6)$ & & \\
\hline Female & 47 & 63 (37.6) & 28 & 37 (24.6) & 75 & $100(31.4)$ & & \\
\hline Total & 125 & $52(100)$ & 114 & $48(100)$ & 239 & $100(100)$ & & \\
\hline Age (years) & & & & & & & 0.99 & 0.8 \\
\hline $18-30$ & 14 & 45 (17.7) & 17 & $55(19.1)$ & 31 & $100(18.4)$ & & \\
\hline $31-40$ & 30 & $45(38)$ & 37 & 55 (41.6) & 67 & $100(39.9)$ & & \\
\hline $41-50$ & 21 & 47 (26.6) & 24 & $53(26.9)$ & 45 & $100(26.8)$ & & \\
\hline $51-60$ & 14 & $56(17.7)$ & 11 & $44(12.4)$ & 25 & 100 (14.9) & & \\
\hline Total & 79 & 47 (100) & 89 & $53(100)$ & 168 & $100(100)$ & & \\
\hline Education & & & & & & & 30.3 & $0.0001 * *$ \\
\hline No education & 0 & $0(0)$ & 7 & $100(6.2)$ & 7 & $100(3.0)$ & & \\
\hline Primary & 1 & $11(0.8)$ & 8 & $88(7.0)$ & 9 & $100(3.8)$ & & \\
\hline Secondary & 10 & $42(8.1)$ & 14 & $58(12.4)$ & 24 & $100(10.2)$ & & \\
\hline Higher & 12 & $31(9.8)$ & 27 & 69 (23.9) & 39 & $100(16.5)$ & & \\
\hline University & 100 & $64(81.3)$ & 57 & $36(50.5)$ & 157 & $100(66.5)$ & & \\
\hline Total & 123 & $52(100)$ & 113 & $48(100)$ & 236 & $100(100)$ & & \\
\hline Length of stay in US & & & & & & & 12.3 & $0.015^{*}$ \\
\hline $0-1$ year & 7 & $39(5.7)$ & 11 & $61(10.4)$ & 18 & $100(7.8)$ & & \\
\hline $1.1-3.0$ years & 19 & $50(15.3)$ & 19 & $50(17.9)$ & 38 & $100(16.5)$ & & \\
\hline $3.1-5.0$ years & 14 & $39(11.3)$ & 22 & $61(20.8)$ & 36 & $100(15.7)$ & & \\
\hline $5.1-10.0$ years & 47 & $54(37.9)$ & 40 & $46(37.7)$ & 87 & $100(37.8)$ & & \\
\hline $11+$ years & 37 & $73(29.8)$ & 14 & $27(13.2)$ & 51 & $100(22.2)$ & & \\
\hline Total & 124 & $54(100)$ & 106 & $46(100)$ & 230 & $100(100)$ & & \\
\hline Length of stay in Philadelphia & & & & & & & 6.7 & 0.15 \\
\hline $0-1$ year & 16 & $47(12.9)$ & 18 & $53(17.0)$ & 34 & $100(14.8)$ & & \\
\hline $1.1-3.0$ years & 25 & $61(20.2)$ & 16 & $39(15.1)$ & 41 & $100(17.8)$ & & \\
\hline $3.1-5.0$ years & 22 & $35(17.7)$ & 27 & $55(25.5)$ & 49 & $100(21.3)$ & & \\
\hline $5.1-10.0$ years & 36 & $51(29.0)$ & 34 & $49(32.1)$ & 70 & $100(30.4)$ & & \\
\hline $11+$ years & 25 & $69(20.2)$ & 11 & $31(10.3)$ & 36 & $100(15.7)$ & & \\
\hline Total & 124 & 54 (100) & 106 & 46 (100) & 230 & $100(100)$ & & \\
\hline Home country SES & & & & & & & 6.3 & 0.09 \\
\hline Very well to do & 14 & $50(11.2)$ & 14 & $50(12.3)$ & 28 & $100(11.7)$ & & \\
\hline Well to do & 60 & $47(48)$ & 69 & $53(60.5)$ & 129 & $100(54.0)$ & & \\
\hline Average & 37 & 59 (29.6) & 26 & $41(22.8)$ & 63 & $100(26.4)$ & & \\
\hline Poor & 14 & $74(11.2)$ & 5 & $26(4.4)$ & 19 & $100(7.9)$ & & \\
\hline Total & 125 & $52(100)$ & 114 & $48(100)$ & 239 & $100(100)$ & & \\
\hline Philadelphia SES & & & & & & & 14.4 & $0.002 *$ \\
\hline Very well to do & 9 & $30(7.3)$ & 21 & 70 (18.6) & 30 & $100(12.7)$ & & \\
\hline Well to do & 75 & $50(60.5)$ & 75 & $50(66.4)$ & 150 & $100(63.3)$ & & \\
\hline Average & 34 & $68(27.4)$ & 16 & $32(14.1)$ & 50 & $100(21.0)$ & & \\
\hline Poor & 6 & $86(4.8)$ & 1 & $14(0.9)$ & 7 & $100(3.0)$ & & \\
\hline Total & 124 & $52(100)$ & 113 & $48(100)$ & 237 & $100(100)$ & & \\
\hline Employment & & & & & & & 7.1 & $0.008 *$ \\
\hline Yes & 97 & $57(78.9)$ & 72 & $43(63.2)$ & 169 & $100(70.7)$ & & \\
\hline No & 26 & 38 (21.1) & 42 & $62(36.8)$ & 68 & $100(28.3)$ & & \\
\hline
\end{tabular}


Table 1 continued

\begin{tabular}{|c|c|c|c|c|c|c|c|c|}
\hline \multirow[t]{2}{*}{ Variable } & \multicolumn{2}{|c|}{ Anglophone } & \multicolumn{2}{|c|}{ Francophone } & \multicolumn{2}{|c|}{ Total } & \multirow[t]{2}{*}{$\chi^{2}$} & \multirow[t]{2}{*}{$P$ value } \\
\hline & \# & $\%$ row $(\% \mathrm{col})$ & $\#$ & \%row (\%col) & $\#$ & $\%$ row $(\% \mathrm{col})$ & & \\
\hline Total & 123 & $52(100)$ & 114 & $48(100)$ & 237 & $100(100)$ & & \\
\hline Occupation & & & & & & & 6.9 & $0.03 *$ \\
\hline Student & 33 & $56(27.3)$ & 26 & $44(23.9)$ & 59 & $100(26.3)$ & & \\
\hline Professional & 67 & $58(55.4)$ & 48 & $42(44.0)$ & 109 & $100(48.7)$ & & \\
\hline Other(self-employed) & 21 & $38(17.3)$ & 35 & $62(32.1)$ & 56 & $100(25.0)$ & & \\
\hline Total & 121 & $54(100)$ & 109 & $46(100)$ & 224 & $100(100)$ & & \\
\hline Religious affiliation & & & & & & & 51.3 & $0.0001 * *$ \\
\hline Christian & 111 & $68(89.5)$ & 53 & $32(46.9)$ & 164 & $100(69.2)$ & & \\
\hline Moslem & 10 & $16(8.1)$ & 51 & $84(45.1)$ & 61 & $100(25.7)$ & & \\
\hline Native African & 1 & $17(0.8)$ & 5 & $83(4.4)$ & 6 & $100(2.5)$ & & \\
\hline Other & 1 & $50(0.8)$ & 1 & $50(0.9)$ & 2 & $100(0.8)$ & & \\
\hline None & 1 & $25(0.8)$ & 3 & $75(2.7)$ & 4 & $100(1.7)$ & & \\
\hline Total & 124 & $55(100)$ & 113 & $45(100)$ & 226 & $100(100)$ & & \\
\hline English proficiency & & & & & & & 95.5 & $0.0001 * *$ \\
\hline Not write or speak & 1 & $13(0.8)$ & 7 & $87(6.1)$ & 8 & $100(3.4)$ & & \\
\hline Speak some not write & 1 & $13(0.8)$ & 7 & $87(6.1)$ & 8 & $100(3.4)$ & & \\
\hline Write and speak moderate & 3 & $5(2.5)$ & 54 & $95(47.4)$ & 57 & $100(24.1)$ & & \\
\hline Speak not write & 2 & $18(1.6)$ & 9 & $82(7.9)$ & 11 & $100(4.6)$ & & \\
\hline Speak and write & 116 & $75(94.3)$ & 39 & $25(32.5)$ & 155 & $100(64.5)$ & & \\
\hline Total & 123 & $52(100)$ & 116 & $48(100)$ & 239 & $100(100)$ & & \\
\hline French proficiency & & & & & & & 163.5 & $0.0001 * *$ \\
\hline Not write or speak & 84 & $98(67.7)$ & 2 & $2(1.8)$ & 86 & $100(36.1)$ & & \\
\hline Speak some not write & 21 & $81(17.0)$ & 5 & $19(4.4)$ & 26 & $100(10.9)$ & & \\
\hline Write and speak moderate & 10 & $46(8.1)$ & 12 & $54(10.5)$ & 22 & $100(9.2)$ & & \\
\hline Speak not write & 5 & $33(4.0)$ & 10 & $67(8.8)$ & 15 & $100(6.4)$ & & \\
\hline Speak and write & 4 & $5(3.2)$ & 85 & $95(74.5)$ & 89 & $100(37.4)$ & & \\
\hline Total & 124 & $52(100)$ & 114 & $48(100)$ & 238 & $100(100)$ & & \\
\hline Where health need received & & & & & & & 53.5 & $0.0001 * *$ \\
\hline Emergency room & 28 & $62(24.0)$ & 17 & $38(18.0)$ & 45 & $100(21.0)$ & & \\
\hline Community health & 22 & $48(19.0)$ & 24 & $52(25.0)$ & 46 & $100(22.0)$ & & \\
\hline Traditional clinic & 3 & $21(3.0)$ & 11 & $79(11.0)$ & 14 & $100(7.0)$ & & \\
\hline Buy/order traditional medicine & 3 & $21(3.0)$ & 11 & $79(11.0)$ & 14 & $100(7.0)$ & & \\
\hline Western trained African physician & 1 & $7(1.0)$ & 14 & $93(15.0)$ & 15 & $100(7.0)$ & & \\
\hline Primary care physician & 44 & $88(38.0)$ & 6 & $12(6.0)$ & 50 & $100(23.0)$ & & \\
\hline Nowhere & 9 & $45(8.0)$ & 11 & $55(11.0)$ & 20 & $100(9.0)$ & & \\
\hline Other & 7 & $79(6.0)$ & 2 & $21(2.0)$ & 9 & $100(4.0)$ & & \\
\hline Total & 117 & $(100)$ & 96 & $(100)$ & 213 & $(100)$ & & \\
\hline
\end{tabular}

* Statistically significant at $P<0.05$ level

** Statistically significant at $P<0.001$ level

seeking health care because of poverty, lack of medical insurance, and difficulty understanding English. Our study exhibited similar observations, but with FPs being the most affected. Whereas APs in Philadelphia identified members of the host culture as culturally insensitive, FPs felt that the immigrants were not willing to accept the host culture and were not readily integrating themselves into mainstream culture. Yet, FPs as a group interacted mostly with people from their own countries and more specifically, with their own ethnic groups in comparison to APs. While FPs were aware of inherent cultural problems in acculturation, they felt powerless to make real changes. 
Fig. 1 Perceived barriers to access

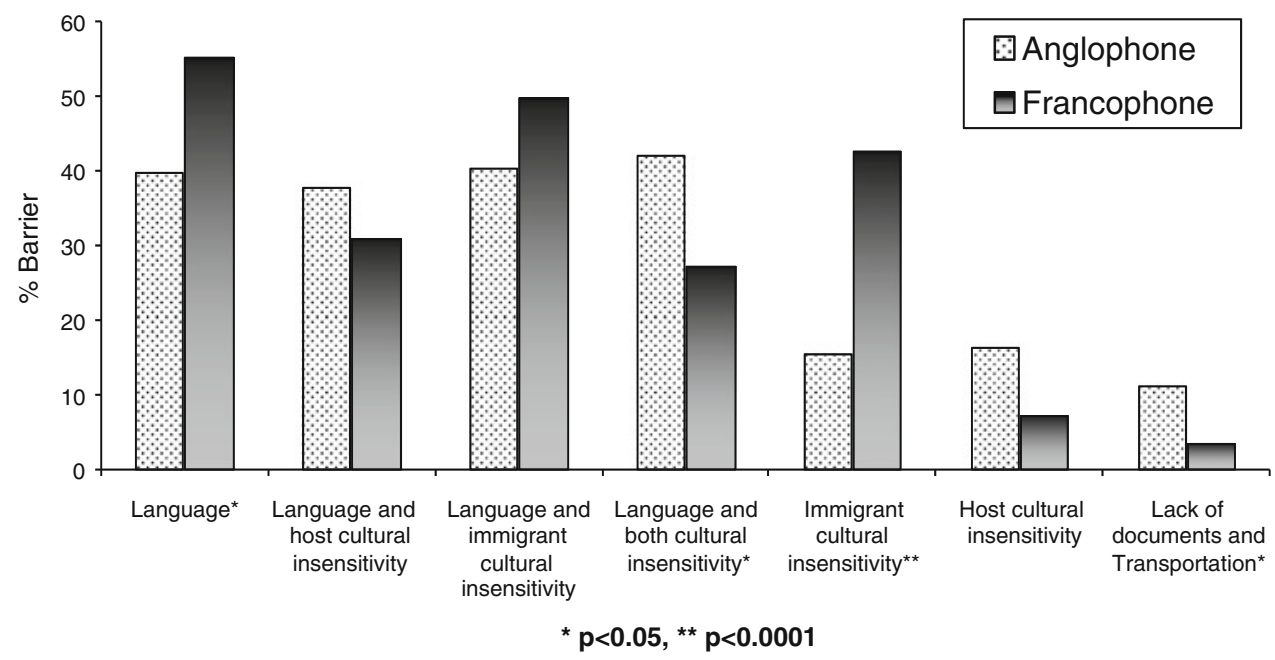

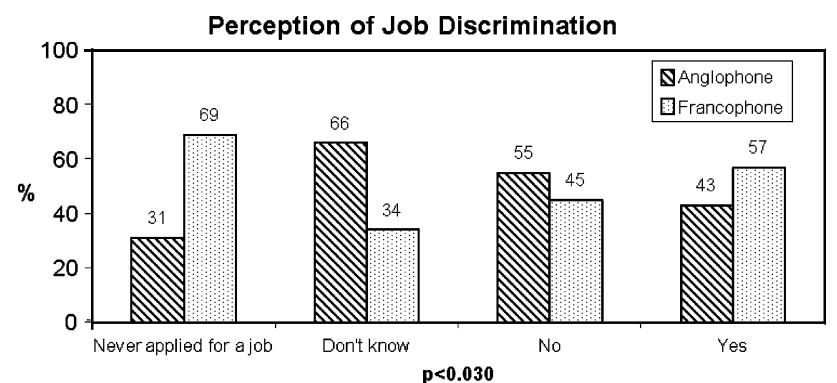

Fig. 2 Perception of job discrimination by Anglophone and Francophone Africans in Philadelphia

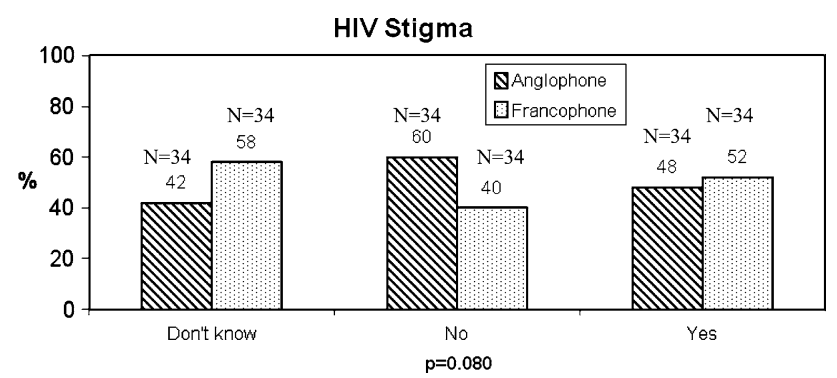

Fig. 3 HIV stigma among Anglophone and Francophone Africans living in Philadelphia

Language, and more specifically comprehension, was a critical factor in the utilization of health care. Interpreters were available to address basic language differences; however, their lack of medical training was a barrier to comprehension. We observed interactions where patients' blank looks were taken as agreement or understanding of the medical issues or implications involved. This observation was also made with APs who were not fluent in English. We observed that the length of stay in the US was not as critical as language proficiency in terms of access to care (Table 1). It is significant to note that coming from an English speaking country did not mean one was an English speaker. There were those from AP countries who spoke very little English and thus had similar language problem as FP immigrants. One social worker concurred that some of the patients acted as if they understood the directions given, only to do the opposite or do nothing; then claiming on the next appointment that they did not understand, yet they had not requested clarity.

In most of Africa, the medical field is viewed as an elite profession with medical professionals held in high esteem akin to the traditional medicine men from earlier generations; their actions and requests are beyond reproach or questioning. The patients with these backgrounds are used to a role as passive users with little personal say in their health care. When encountering a health care system where they are expected to contribute to their own well-being by health care centers that seemed more efficacious compared to what they had been used to, they became paralyzed by their own cultural habits.

\section{Limitations}

The main limitations of the study are the non-randomized sampling method used and the small sample size. The logistics of this special situation created these issues and therefore the interpretation and generalizability of the results suffer directly. The same issues restricted models adjusting for demographics or confounding factors to the extent that they could not be entertained. The findings of this project warrant future investigation utilizing a larger sample and randomized sampling protocol. Other limitations involve the language barrier and the ethics of 
Table 2 Social support and social network among Anglophone and Francophone Africans in Philadelphia

\begin{tabular}{|c|c|c|c|c|c|c|}
\hline Region & Anglophone & Francophone & To & & Value & $\chi^{2}$ \\
\hline \# Variable & $\begin{array}{l}\% \text { row } \\
(\% \text { col })\end{array}$ & $\begin{array}{l}\% \text { row } \\
(\% \text { col })\end{array}$ & \# & $\begin{array}{l}\text { \%row } \\
(\% \mathrm{col})\end{array}$ & & \\
\hline
\end{tabular}

1 Someone to share secret worries and fears

Never

Sometimes

Most of the time

All of the time

Total

2 Someone to help resolve problem

Never

Sometimes

Most of the time

All of the time

Total

3 Trust of Philadelphia city government

Hardly ever

Some of the time

Most of the time

Always

Total

4 Have you been in the home of a friend of different race in the past 12 months

Don't remember

No

Yes

Total

5 Have you been in the home of a friend of different religion in the past 12 months

Don't remember

No

Yes

Total

6 How often have you attended religious services in the past 12 months

Don't know

Few times per year

Once or twice per month

Almost once per week

Once or more per week

Total

7 What language do you use at home?

Ethnic
French
English
Ethnic/French
Ethnic/French/English
Ethnic/English
French/English
Total

$\begin{array}{rcrcrc}20 & 49(16.4) & 21 & 51(18.9) & 41 & 100(17.6) \\ 64 & 49(52.5) & 65 & 51(58.6) & 129 & 100(55.4) \\ 26 & 62(21.3) & 16 & 38(14.4) & 42 & 100(18.0) \\ 12 & 57(9.8) & 9 & 43(8.1) & 21 & 100(9.0) \\ 122 & (100) & 111 & (100) & 233 & (100)\end{array}$

\section{1}

64

$48(9.0)$

49 (52.5)

30

17

122

$59(24.6)$

59 (13.9)

(100)

$$
12
$$

$52(10.7)$

23

$51(59.5) \quad 130$

$41(18.9) \quad 51$

$41(10.8) \quad 29$

(100)

233

$\begin{array}{rrr}15 & 31(13.5) & 33 \\ 60 & 63(54.1) & 35 \\ 22 & 43(19.8) & 29 \\ 14 & 58(12.6) & 10 \\ 111 & (100) & 107\end{array}$

$69(30.8)$

37 (32.7)

57 (27.1)

$42(9.3)$

(100)

107

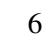

38

77

121

$38(5.0)$

40 (31.4)

10

$62(9.0)$

$60(52.3)$

64 (63.6)

(100)

$36(38.7)$

(100)

111

7
49

49
66

122

47 (5.7)

45 (40.2)

63 (54.1)

(100)

8
61
39
108

$$
53 \text { (7.4) }
$$$$
55 \text { (56.5) }
$$

15

37 (36.1)

110

(100)

$$
105
$$

230

$\begin{array}{rcr}10 & 45(8.3) & 12 \\ 15 & 39(12.4) & 24 \\ 20 & 51(16.5) & 19 \\ 28 & 67(23.1) & 14 \\ 48 & 55(39.7) & 39 \\ 121 & (100) & 108\end{array}$

55 (11.1)

61 (22.2)

22

49 (17.6)

33 (13.0)

45 (36.1)

(100)

16
96
120
232

100 (41.4)

100 (51.7)

(100)

$100(6.5)$

$100(47.8)$

$100(45.7)$

(100)

$7.17 \quad 0.130$

100 (9.6)

$100(17.0)$

$100(17.0)$

100 (18.2)

100 (38.0)

(100)

49 (19.6) 43

$100(18.8)$

$100(9.2)$

$100(25.3)$

$100(9.6)$

$100(10.9)$

$100(21.0)$

100 (5.2)

(100)

$14.4 \quad 0.001 * *$

$7.49 \quad 0.020 *$

$124.40 .000^{* *}$ 
Table 2 continued

\begin{tabular}{|c|c|c|c|c|c|c|}
\hline Region & Anglophone & Francophone & & & Value & $\chi^{2}$ \\
\hline \# Variable & $\begin{array}{l}\% \text { row } \\
(\% \text { col })\end{array}$ & $\begin{array}{l}\% \text { row } \\
(\% \text { col })\end{array}$ & \# & $\begin{array}{l}\text { \%row } \\
(\% \text { col })\end{array}$ & & \\
\hline
\end{tabular}

8 What language do you use with friends?

$\begin{array}{lrcrrrr}\text { Ethnic } & 13 & 45(10.7) & 16 & 55(14.7) & 29 & 100(12.6) \\ \text { French } & 0 & 0(0.0) & 28 & 100(25.7) & 28 & 100(12.1) \\ \text { English } & 67 & 91(54.9) & 7 & 9(6.4) & 74 & 100(32.0) \\ \text { Ethnic/French } & 0 & 0(0.0) & 21 & 100(19.3) & 21 & 100(9.1) \\ \text { Ethnic/French/English } & 2 & 9(1.6) & 20 & 91(18.3) & 22 & 100(9.5) \\ \text { Ethnic/English } & 38 & 95(31.2) & 2 & 5(1.8) & 40 & 100(9.5) \\ \text { French/English } & 2 & 12(1.6) & 15 & 88(13.8) & 17 & 100(7.4) \\ \text { Total } & 122 & (100) & 109 & (100) & 231 & (100)\end{array}$

$154.8 \quad 0.000^{* *}$

Involvement in ethnic community organizations

Never

Some of the time

Most of the time

Always

Total

$\begin{array}{rrrrrr}24 & 47(20.2) & 27 & 53(24.8) & 51 & 100(22.4) \\ 63 & 70(53.0) & 27 & 30(24.8) & 90 & 100(39.5) \\ 14 & 40(11.8) & 21 & 60(19.4) & 35 & 100(15.5) \\ 18 & 35(15.0) & 34 & 65(31.2) & 52 & 100(22.8) \\ 119 & (100) & 109 & (100) & 228 & (100)\end{array}$

$20.5 \quad 0.000^{* *}$

10 Involvement in American community organizations

Never

Some of the time

Most of the time

Always

Total

$\begin{array}{rcr}52 & 41(43.0) & 74 \\ 57 & 74(47.1) & 20 \\ 9 & 39(7.4) & 14 \\ 3 & 50(2.5) & 3 \\ 121 & (100) & 111\end{array}$

$59(66.7) \quad 126$

$100(54.3)$

100 (33.2)

$61(12.6) \quad 23 \quad 100(9.9)$

$50(2.7) \quad 6$

$100(2.6)$

(100)

11 Do you befriend individuals from your ethnic group?

Never

Some of the time

Most of the time

Always

Total

$\begin{array}{rcr}9 & 43(7.4) & 12 \\ 51 & 65(41.8) & 27 \\ 35 & 52(28.7) & 33 \\ 27 & 42(22.1) & 38 \\ 122 & (100) & 110\end{array}$

$\begin{array}{rr}57(11.0) & 21 \\ 35(24.5) & 78 \\ 48(30.0) & 68 \\ 58(34.5) & 65 \\ (100) & 232\end{array}$

$100(9.1)$

100 (33.6)

$100(29.3)$

$100(28.0)$

(100)

12 Do you befriend Americans?

Never

$\begin{array}{rcrcr}11 & 37(9.2) & 19 & 63(17.2) & 30 \\ 67 & 55(55.8) & 55 & 45(49.5) & 122 \\ 26 & 48(21.7) & 28 & 52(25.2) & 54 \\ 16 & 64(13.3) & 9 & 36(8.1) & 25 \\ 120 & (100) & 111 & (100) & 231\end{array}$

$100(13.0)$

$100(52.8)$

Some of the time

Most of the time

Always

(100)

(100)

$100(23.4)$

$100(10.8)$

(100)

$22.320 .000^{* *}$

$9.14 \quad 0.030^{*}$

o you spend most of your free time with individuals from your own ethnic group?

\begin{tabular}{lllllrl} 
Never & 7 & 39 & 11 & $61(10.0)$ & 18 & $100(7.8)$ \\
Some of the time & 69 & 64 & 39 & $36(35.5)$ & 108 & $100(46.8)$ \\
Most of the time & 32 & 46 & 38 & $54(34.5)$ & 70 & $100(30.3)$ \\
Always & 13 & 37 & 22 & $63(20.0)$ & 35 & $100(15.1)$ \\
Total & 121 & $(100)$ & 110 & $(100)$ & 231 & $(100)$ \\
\hline
\end{tabular}


Table 2 continued

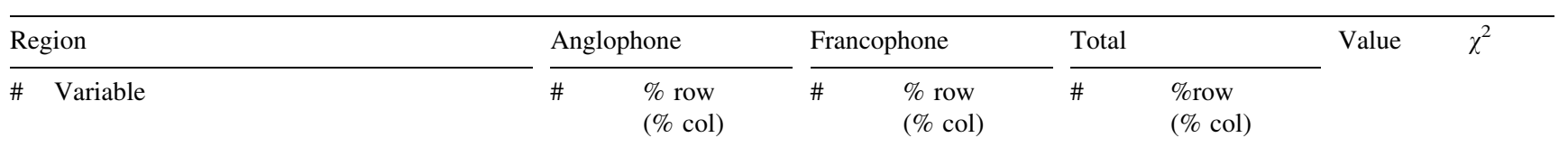

14 Do you spend most of your free time with Americans?

Never
Some of the time
Most of the time
Total

$\begin{array}{rcrcrc}15 & 31(12.4) & 33 & 69(30.3) & 48 & 100(20.9) \\ 88 & 66(72.7) & 45 & 34(41.3) & 133 & 100(57.8) \\ 13 & 35(10.7) & 24 & 65(22.0) & 37 & 100(16.1) \\ 5 & 42(4 . .2) & 7 & 58(6.4) & 12 & 100(5.2) \\ 121 & (100) & 109 & (100) & 230 & (100)\end{array}$

15 Do you trust people in your neighborhood?

Not very often

Some of the time

Most of the time

Total

$\begin{array}{rc}19 & 45(15.6) \\ 58 & 62(47.6) \\ 30 & 56(24.6) \\ 15 & 36(12.2) \\ 122 & (100)\end{array}$

23

$55(20.9)$

(1)

$100(18.0)$
$100(40.5)$
$100(23.3)$
$100(18.1)$
$(100)$

9.03

0.29

$38(32.7) \quad 94$

$44(21.8) \quad 54$

23.69

$0.000^{* *}$

16 Do you trust African Americans in your neighborhood?

Not at all
Not very often
Some of the time
Most of the time
Total

$\begin{array}{rcrrrr}7 & 16(5.7) & 36 & 84(32.7) & 43 & 100(18.5) \\ 49 & 63(40.2) & 29 & 37(26.4) & 78 & 100(33.6) \\ 54 & 65(44.3) & 29 & 35(26.4) & 83 & 100(35.8) \\ 12 & 43(9.8) & 16 & 57(14.5) & 28 & 100(12.1) \\ 122 & (100) & 110 & (100) & 232 & (100)\end{array}$

17 Do you trust members of other races in your community?

Not at all
Not very often
Some of the time
Most of the time
Total

$\begin{array}{rc}8 & 40(6.7) \\ 41 & 58(34.2) \\ 65 & 61(54.1) \\ 6 & 19(5.0) \\ 120 & (100)\end{array}$

$\begin{array}{crc}60(10.9) & 20 & 100(8.6) \\ 42(27.3) & 71 & 100(30.9) \\ 39(38.2) & 107 & 100(46.5) \\ 81(23.6) & 32 & 100(14.0) \\ (100) & 230 & (100)\end{array}$

$19.550 .000 * *$

18 Do you trust members of your own country in your community?

$\begin{array}{lrrrrrr}\text { Not at all } & 6 & 50(5.0) & 6 & 50(5.5) & 12 & 100(5.2) \\ \text { Not very often } & 21 & 44(17.4) & 27 & 56(24.5) & 48 & 100(20.8) \\ \text { Some of the time } & 74 & 66(61.2) & 39 & 34(35.5) & 113 & 100(48.9) \\ \text { Most of the time } & 20 & 35(16.5) & 38 & 65(34.5) & 58 & 100(25.1) \\ \text { Total } & 121 & (100) & 110 & (100) & 231 & (100)\end{array}$

* Statistically significant at $P<0.05$ level

** Statistically significant at $P<0.001$ level

sensitive questions and issues common in HIV/AIDS research.

\section{Conclusion}

This study highlights the difference in the perceptions of access to health care and social services among APs and FPs in Philadelphia. The study showed that though most studies still group Africans and African-Americans together, the two groups behave differently, and thus should be considered separately. This study shows that even among immigrants from same continent and country; variables such as cultural experience, language, and religious differences influence their access to health care when they move to the US. Whereas the more recent FP immigrants considered lack of documentation and immigrant cultural insensitivity as major barriers, APs who had lived longer in 
the US reported host cultural insensitivity and transportation to be the barriers to access to health care. Both communities mentioned HIV stigma and discrimination as a real barrier to HIV prevention efforts, which was strong enough to lead some community members to move to other areas in the city. Language was named by both communities to be a more significant barrier to health care access.

Our findings suggest that there is discrepancy in access to health care for immigrant Africans with Anglophone Africans having better access than Francophone Africans. The poor access was mainly due to fear of visiting the health centers because of lack of documents, transportation, language barrier, inadequate familiarity of the system; and in the case of the HIV infected, stigma and discrimination. HIV stigma was strong in both communities and discouraged most infected members from disclosing their sickness, sometimes even to family members. FPs had poorer access than APs and this difference was based on language proficiency, a lack of formal education, and less social support or poor networking. Through site visit interviews we observed that some members of the FP community procured medicines from their own countries for a variety of ailments.

An effective prevention control program in the AP and FP community must be culturally sensitive while involving the key stakeholders of the community. The churches and mosques that remain an integral part of the communities need to be fully engaged in both the development and application of the programs. Involving the church has been shown to be successful by a program started by one AP community that caters to members infected with HIV by finding housing for them, directing them to the health centers, allocating jobs for them, having English classes, and providing social support (personal communication). Providers need a better understanding of the American health care system, along with a vigilance to recognize and address the cultural sensitivities surrounding HIV risk factors and risk perception in these populations. This cultural awareness can produce the educational tools which can be used to combat stigmatization and discrimination of those infected and affected by HIV, while equilibrating the power balance between men and women within the AP and FP communities.

Acknowledgement We are deeply indebted to Tigida Kaba of the African Family Health organization, Ben Fadjo of the Togo community organization, African community organizations, English-speaking African churches, French-speaking African churches, African mosques, Temple University Department of Public Health, and the Philadelphia Department of Health-which partially funded this study. We would also like to thank Richard Dzeng for editing the manuscript.
Open Access This article is distributed under the terms of the Creative Commons Attribution Noncommercial License which permits any noncommercial use, distribution, and reproduction in any medium, provided the original author(s) and source are credited.

\section{References}

1. UNAIDS (2004) Report on the global AIDS epidemic, executive summary, pp 1-18.

2. Rosenthal L, Scott DP, Kelleta Z, Zikarge A, Momoh M, LahaiMomoh J, et al. Assessing the HIV/AIDS health services needs of African immigrants to Houston. AIDS Educ Prev. 2003;15(6): 570-80.

3. Lopes-Velez R, Huerga H, Turrientes MC. Infectious diseases in immigrants from the perspective of a tropical medicine referral unit. Am J Trop Med Hyg. 2003;69(1):115-21.

4. Cookson ST, Carballo M, Nolan CM, Keystone JS, Jong EC. Migrating populations - a closer view of who, why, and so what. Emerg Infect Dis. 2001;7(3):551.

5. Dressler WW. Culture, stress, and disease. In: Johnson TM, Sargent CF, editors. Medical anthropology: contemporary theory and method. New York: Preger; 1990.

6. Robbins JM, Webb DA. Neighborhood poverty, mortality rates, and excess deaths among African Americans: Philadelphia, 1999-2001. J Health Care Poor Underserved. 2004;15(4):530-7.

7. Ashton E, Vosvick M, Chesney M, Gore-Felton C, Koopman C, O'Shea $\mathrm{K}$, et al. Social support and maladaptive coping as predictors of the change in physical health symptoms among persons with HIV/AIDS. AIDS Patient Care STDS. 2005;19(9):587-98.

8. Bouckenooghe AR, Shandera WX. The epidemiology of HIV and AIDS among Central American, South American, and Caribbean Immigrants to Houston, Texas. J Immigr Health. 2002;4(2):81-6.

9. Harawa NT, Bingham TA, Cichran SD, Greenland S, Cunningham WE. HIV prevalence among foreign and US-born clients of STD clinics. Am J Public Health. 2002;92(12):1958-63.

10. Cappon P, Adrien A, Godin G, Singer SM, Maticka-Tyndale E, Willms DG, Daus T. HIV/AIDS in the context of culture: selection of ethnocultural communities for study in Canada. Can J Public Health 1996;87(Suppl 1):S11-4, S11-5.

11. Carballo M, Divino JJ, Zeric DD. Migration and health in the European Union. Tropical Med Int Health. 1998;3(12):936-44.

12. Carballo M, Siem H. Migration, migration policy and AIDS. In: Haour-Knipe M, Rector R, editors. Crossing borders: migration, ethnicity, and AIDS. Taylor \& Francis Publishers; 1996.

13. Burnett A. Globalization, migration and health. Med Confl Surviv. 2002;18(1):34-43.

14. Larson A. The social context of HIV in Africa. Historical and cultural bases of east and central African sexual behaviour. Rev Infect Dis. 1989;11:716-31.

15. McBride DC, Weatherby NL, Inciardi JA, Gillespie SA. AIDS susceptibility in a migrant population: perception of behavior. Subst Use Misuse. 1999;34(4-5):633-52.

16. McKinney MM, Marconi KM. Delivering HIV services to vulnerable populations. a review of CARE Act-funded research. Public Health Rep. 2002;117:99-113.

17. Babbie E. The practice of social research. 9th ed. Belmont, CA: Wadsworth/Thomson Learning, Inc; 2001. 